\title{
¿Por qué se estancó la cabaña trashumante castellana en la segunda mitad del siglo XVIII? Una interpretación
}

\section{Why did get stagnated the Castilian transhumant flock in the second half of the eighteenth century? An interpretation}

\author{
EMILIO PÉREZ ROMERO \\ Universidad Alfonso X el Sabio, Madrid
}

\begin{abstract}
RESUMEN
En este trabajo se examinan las fuentes disponibles para estudiar la evolución cuantitativa de la cabaña trashumante
\end{abstract} castellana durante el siglo XVIII. De ellas se deduce que el número de cabezas creció durante la primera mitad de la centuria para, luego, entrar en una fase estacionaria, probablemente, hasta la guerra de Independencia. Tras constatar que dicho estancamiento coincide con una fase de crecimiento de las exportaciones laneras y de buenos resultados de las explotaciones trashumantes, se propone como principal factor explicativo del mismo la escasez de pastos. En relación con esta hipótesis se analizan la conflictividad por el acceso a los pastizales, los mecanismos a través de los cuales fueron redistribuidos y las formas en que todo ello contribuyó a la gestación de la crisis de la Mesta y de la trashumancia castellana.

PALABRAS CLAVE: ganadería, trashumancia, pastos, Mesta.

\section{ABSTRACT}

First, this article analyses the available sources to study the quantitative evolution of the Castilian transhumant flocks during the eighteenth century. These sources allow concluding that the number of livestock increased during the first half of the century and thereafter, it entered in a stationary stage probably until the Independence War. This stagnation coincided with an increase of the wool exports and with positive results for the transhumant exploitations. Therefore, this paper proposes that the scarcity of pastureland is the main explanation for this stagnation. Related to this hypothesis, the article studies the conflict arising from access to these pasture lands, the ways the land were redistributed and how all these events gave rise to the Mesta and the Castilian transhumance crisis.

KEY WORDS: livestock, trnashumance, pasture, Mesta

JEL Codes: N53, Q15 


\section{Introducción ${ }^{1}$}

E

n la actualidad se considera al Setecientos como el siglo de oro de la trashumancia mesteña ${ }^{2}$. También coinciden los especialistas en que fue en esa centuria cuando el número de ovinos trashumantes alcanzó su máximo histórico en la Corona de Castilla. Sin embargo, aún no está del todo claro cómo evolucionó el tamaño de la cabaña en el transcurso del siglo. Este trabajo pretende reconstruir dicha evolución cuantitativa y determinar cuáles fueron los factores que más incidieron sobre la misma. En relación con ello, también se examinarán los principales cambios que experimentó la distribución territorial de la propiedad de los rebaños y se harán algunas consideraciones sobre la crisis de la Mesta.

Para fijar el número de cabezas trashumantes existentes en distintos momentos del siglo, además de revisar las fuentes ya conocidas, se utilizan otras nuevas que proporcionan cifras o permiten hacer estimaciones fiables. Por lo que se refiere al análisis de la trayectoria seguida por la cabaña en el contexto de crecimiento agrario del siglo XVIII, además de la investigación propia, se tienen en cuenta las aportaciones de la bibliografía más reciente.

\section{Evolución cuantitativa de la cabaña trashumante en el siglo XVIII}

Para el estudio de la evolución cuantitativa de la cabaña trashumante durante el Setecientos disponemos de varios registros o recuentos ganaderos que abarcan todo el territorio de la Corona de Castilla. Fueron recopilados - y uno de ellos realizado- con motivo del pleito que enfrentó a Extremadura y la Mesta, razón por la cual los originales o copias de los mismos se han conservado entre la documentación del expediente elaborado ante el Consejo de Castilla. El Memorial ajustado de 1783 contiene una síntesis de sus datos ${ }^{3}$. Por otro lado, el Catastro de Ensenada proporciona información adicional para los años centrales de la centuria. A partir de estas fuentes es posible calcular, aunque con distinto grado de precisión y fiabilidad, el número de cabezas que trashumaban en 1707, 1746, c. 1750-54, 1765, 1779-80 y 1780-81.

\footnotetext{
$1 \quad$ Agradezco a los evaluadores anónimos todas sus observaciones y sugerencias, en algún caso generosamente minuciosas. Sin duda, en la medida en que haya sido capaz de incorporarlas al texto, éste habrá mejorado. Mi agradecimiento también a Enrique Llopis por su estímulo para que completara este trabajo, hace tiempo iniciado.

2 García Sanz (1994b), p. 138.

3 Memorial ajustado (1783), t. II, ff. 154-165 y planos finales.
} 
CUADRO 1

ESTIMACIONES DEL TAMAÑO DE LA CABAÑA TRASHUMANTE CASTELLANA EN DISTINTAS FUENTES IMPRESAS ${ }^{4}$

\begin{tabular}{llc}
\hline Fecha & \multicolumn{1}{c}{ Autor } & Estimación (cabezas) \\
\hline 1724 & Gerónimo de Uztáriz & 4.000 .000 \\
1740 & Pedro Calatayud & 5.000 .000 \\
1762 & Alonso Cano & 5.000 .000 \\
1764 & William Bowles & 5.000 .000 \\
1789 & Jean François Bourgoing & 5.000 .000 \\
1799 & Charles Philibert Lasteyrie & 4.500 .000 \\
\hline
\end{tabular}

Fuentes: Uztáriz (1968 [1742]), p. 21; Calatayud (1761), p. 69; Cano (1834 [1762]), p. 33; para los datos de Bowles, Phillips y Phillips (1997), p. 289; Bourgoing (1803 [1789]), p. 93; Lasteyrie (1799), pp. 7 y 94.

La falta de datos para los dos últimos decenios del siglo puede cubrirse a partir de algunas cifras procedentes de la administración de la renta de lanas ${ }^{5}$.

Como complemento, disponemos de testimonios coetáneos que ofrecen evaluaciones del tamaño de la cabaña o apreciaciones acerca de su estado y tendencia en diferentes momentos. Por lo que se refiere a las estimaciones que circularon en la época en libros u opúsculos - y que Klein ya consideró inexactas ${ }^{6}$-, parece evidente que tienden a exagerar los efectivos trashumantes y pueden calificarse de literarias porque tienen más de recurso retórico para subrayar la importancia de la trashumancia castellana que de fiel reflejo cuantitativo de la realidad. Resulta tan llamativo como sospechoso que todas ellas coincidan, entre 1724 y 1803, en cifras que oscilan entre los cuatro y los cinco millones de cabezas. Las estimaciones que pueden rastrearse en documentos no destinados a la publicación parecen, en general, más fiables, aunque deben tomarse sólo como referencias aproximadas.

4 Aparte de las que figuran en este cuadro, existe al menos otra fuente impresa que, para un momento indeterminado de la segunda mitad del siglo XVIII, cifraría también la cabaña merina en torno a los 4.000.000 de cabezas. Véase Klein (1936), p. 71.

5 En general, las exportaciones de lana no son un buen indicador de la evolución de la cabaña trashumante. Primero, porque las series elaboradas hasta el momento [Phillips y Phillips (1997), pp. 297-304; Bilbao (1998), p. 331] son fruto de estimaciones a partir de lo recaudado en concepto de derechos de exportación y manifiestan importantes discrepancias para algunos períodos; segundo, porque la lana podía almacenarse durante varios años, de modo que las exportaciones de un ejercicio no pueden identificarse, sin más, con la producción del mismo; y tercero, y más importante, porque la correspondencia entre la lana producida por el ganado trashumante y la lana exportada no era biunívoca [García Sanz (1994a), pp. 401-409]. 


\subsection{Datos procedentes de la administración del "servicio y montazgo"}

En 1709, a partir de los libros en que, mientras estuvo vigente el servicio y montazgo, se registraba anualmente el ganado trashumante a su paso por los puertos, el administrador de dicha renta elaboró una relación con los datos correspondientes al ejercicio de 1707-087. La suma de los 1.003 asientos de que consta arroja un total de 2.116.512 cabezas $^{8}$. Dado que se anotaron de forma indiferenciada ovejas y cabras (estas últimas solían representar en torno al 4 ó 5 por 100 de las reses ) y que hay varios asientos imprecisos, lo más que se puede afirmar es que el número de cabezas lanares que cruzaron los puertos cañada abajo entre septiembre y diciembre de 1707, es decir, cuando el tamaño de la cabaña se acercaba a sus mínimos anuales, se situó en torno a los 2.000.000. El número no es exacto, pero sí fiable, dado el grado de detalle con que la fuente ofrece los datos.

Aunque se limitan a cifras globales, parecida validez puede atribuirse a otras dos estimaciones que también se basan en los registros para la recaudación del servicio y montazgo. La primera, que se deduce de un escrito del Honrado Concejo, arroja entre 2.500 .000 y 2.600 .000 cabezas para 1725-26, antes de la gran mortandad de ganado que se produjo al año siguiente ${ }^{9}$. La segunda, más precisa, fija en 3.294.136 las cabezas registradas en 1746 "al subir a las sierras"10. En relación con esta última, de ser correcta la precisión temporal, nos encontraríamos ante un tamaño anual máximo de la cabaña, al incluir las crías nacidas en el invernadero y los carneros que, "cañada arriba", se vendían en Madrid y su entorno. Como la cifra, seguramente, también computa las cabras, restando éstas, quedarían 3.144 .000 cabezas ovinas.

\subsection{Catastro de Ensenada}

El Catastro de Ensenada constituye, tras el registro de 1707, la segunda mejor fuente disponible para el siglo XVIII. Si bien lo ideal sería recoger la información en su primer nivel de elaboración, es decir, de las relaciones particulares en los libros de lo real, aquí sólo se utilizarán los datos agregados de los Mapas o Estados Generales ${ }^{11}$, en concreto de los estados $H$ de cada provincia, que informan, pueblo por pueblo, del número de cabezas de cada especie que pastaban "en el término" o "fuera de él".

\footnotetext{
Archivo Histórico Nacional (en adelante, AHN), Consejos, leg. 7.087.

El autor de la relación computó 2.098 .512 cabezas, es decir, 18.000 menos de las que resultan de mi suma. AHN, Mesta, leg. 248/63.

Memorial ajustado (1783), t. II, f. $163 \mathrm{v}$.

AHN, Fondos Contemporáneos, Hacienda, libros 7.401-7.509.
} 
Pese a su calidad, esta fuente no está exenta de problemas y limitaciones. Primero, ni se han conservado los estados $H$ de todas las provincias, ni éstos distinguen siempre entre el ganado que pastaba dentro y el que lo hacía fuera del término municipal correspondiente ${ }^{12}$. Segundo, las cabezas que pastaban "fuera del término", no eran, necesariamente, trashumantes: podía tratarse de ganado que realizaba desplazamientos cortos, es decir, transterminante o riberiego, o que se movía al margen de los circuitos mesteños. Tercero, los datos de las distintas provincias no sólo no están referidos a una misma fecha (las averiguaciones se desarrollaron entre 1750 y $1754^{13}$ ), sino que, además, se recogieron en distintas estaciones, lo que tiene gran trascendencia para el cómputo de los efectivos ganaderos. Por último, es difícil determinar hasta qué punto los datos catastrales acusan las dos mortandades extraordinarias de ganado que se produjeron durante la primera mitad de los años cincuenta, en las invernadas de 1750 a $1751^{14}$ y de 1752 a 1753; si bien las intervenciones de algunos ganaderos en la junta de la Mesta de mayo de 1753 permiten suponer que buena parte de la información que contienen los mapas había sido recogida antes de la segunda —y más importante- de dichas crisis $^{15}$.

Pese a estos inconvenientes, cabe considerar que los datos catastrales reflejan con razonable fidelidad la situación de la cabaña trashumante en la primera mitad del decenio de 1750, tanto por lo que se refiere a su tamaño como a la distribución geográfica y social de su propiedad. La salvedad más importante se refiere al ganado que pastaba "fuera del término" en las antiguas provincias andaluzas, cuyo carácter trashumante es sumamente improbable ${ }^{16}$. En consecuencia, la información catastral permite establecer un mínimo de 3.100 .000 y un máximo de 3.250.000 cabezas de lanar trashumante, según se incluya o no el ganado andaluz.

12 Faltan por completo los de Burgos, Córdoba y Toledo, el de seculares de Guadalajara (dentro de las provincias del Reino de Galicia, también falta el de Orense) y el de eclesiásticos de Jaén. La carencia es especialmente grave por lo que se refiere a Burgos y Guadalajara, dado que ambas provincias contaban con importantes contingentes de ganado trashumante. En Extremadura, Galicia y Murcia no se distingue entre el ganado que pastaba "en el término" y el que lo hacía "fuera de él". Para suplir estas deficiencias, he estimado 340.000 cabezas para Burgos, 200.000 para Guadalajara y 30.000 para Extremadura; para Toledo he tomado las 106.614 cabezas computadas a partir de otros niveles catastrales [Donézar (1984), pp. 176-178] y les he sumado las 25.289 con que contaba el monasterio de Guadalupe en 1750 [Llopis (1993), p. 129]. No he hecho estimación alguna para las demás provincias, dado que con anterioridad a la elaboración del Catastro no hay noticias de la existencia en las mismas de cabañas de entidad que practicasen una trashumancia directa.

13 Camarero (1989), p. 368.

14 Las fuentes, cuando hablan de esta crisis, suelen referirla al año 1750. Por ejemplo, AHN, Mesta, leg. 516, Libro de Acuerdos, f. 22v; y leg. 250/6-12, Memorial, 7 de junio de 1758.

15 AHN, Mesta, leg. 516, Libro de Acuerdos, ff. 113v-114v, 120v-121, 136v-138v.

16 Los respectivos mapas $H$ registran 2.330 cabezas en Granada (en las actuales provincias de Almería, Granada y Málaga) y 155.149 en Sevilla (en las actuales provincias de Cádiz, Huelva, Málaga y Sevilla). 
Estas cifras son congruentes con la de 1746 y con la opinión de los propios ganaderos, quienes, hacia 1752, estimaban que la cabaña contaría con unos 3.000 .000 de cabezas ${ }^{17}$.

\subsection{Relaciones de ganaderos para los repartimientos de 1765 y 1776}

En 1765, el Honrado Concejo acordó contribuir al abastecimiento de la Corte con 50.000 fanegas de trigo procedentes del pósito de San Clemente (Cuenca). Para sufragar la operación se hizo un repartimiento entre "todos los ganaderos que goza[ba]n de los privilegios de la Mesta", a razón de cuatro maravedíes por cabeza de ganado, independientemente de la especie y de que trashumase o no. Esta última circunstancia hizo que, al confeccionar las relaciones de contribuyentes, muchos alcaldes de cuadrilla no distinguiesen entre ganado estante y trashumante, lo que impide, basándose en ellas, establecer con seguridad el tamaño que tenía la cabaña trashumante en $1765^{18}$. La cifra de 3.500 .000 que habitualmente se acepta para dicho año puede resultar plausible, pero ha de quedar claro que no es el fruto de un recuento - como, a veces, se presenta - sino una mera estimación hecha por el Honrado Concejo $^{19}$.

Dos testimonios, uno del principio y otro del final de la década de los setenta, trasladan la impresión de que la cabaña se había estancando desde mediados de siglo. En 1771, el anónimo autor de la Carta de Ynstrucción Práctica de un ganadero..., afirmaba que, veinte años después de las grandes mortandades de 1750-53, la cabaña aún no se había repuesto de sus efectos ${ }^{20}$, y en 1779 , los ganaderos de la cuadrilla de Cuenca consideraban que de las cabezas registradas en 1746, "aunque en el día se le rebaje el pico por la notoria decadencia", quedarían 3.000.00021.

En 1776, la Mesta decidió realizar un nuevo repartimiento para atender los gastos que le estaba ocasionando el pleito con Extremadura. En esta ocasión, los ganaderos estantes de muchas cuadrillas serranas se resistieron con éxito al pago que se les exigía e, incluso, lograron que se les permitiera abandonar el Honrado Concejo.

17 Los mesteños calcularon que en el invierno de 1752 a 1753 “habían perdido la mitad de sus ganados, sin exageración, pues pasaban de millón y medio de cabezas las que hasta aquí habían muerto, con lamentable ruina de sus dueños" (AHN, Mesta, leg. 249/29). Quizá exageraran las pérdidas, pero no tenían por qué hacer lo mismo con el número de cabezas existentes antes de la crisis.

18 AHN, Mesta, leg. 282 y Consejos, leg. 7.088; Memorial ajustado (1783), t. II, f. 157v.

19 Memorial ajustado (1771), f. 73v; Memorial ajustado (1783), t. II, ff. 163v-164.

20 Carta de Ynstrucción Práctica de un Ganadero trasum..$^{\text {te }}$ exponiendo el dictamen q. ${ }^{e}$ se le pidio sobre el Recurso consultivo a la Mag. ${ }^{\text {y }}$ Pretensiones de la Provincia de Extremad. ${ }^{a}$ contra las de las Sierr.s de Castilla, y León, y Derogación de los Privilexios, q.e conservan sus Ganados Lanares Finos trasumantes, (Real Academia de la Historia, Manuscritos, 9-26-8-D-196), p. 178r.

$21 \quad$ AHN, Mesta, leg. 335. 
Cuando, en marzo de 1780, el Procurador General de la Mesta trató de establecer el tamaño de la cabaña a partir de las listas de recaudación de este repartimiento, comprobó que era imposible porque sólo habían pagado lo que les correspondía 64 grandes ganaderos (912.115 cabezas) y 58 cuadrillas serranas (1.447.362 cabezas, sin distinción entre estantes y trashumantes $)^{22}$. No obstante, "por conjeturas" y a la vista de repartimientos anteriores y "demás noticias" a su disposición, aventuró que "los verdaderos serranos" poseerían por entonces 2.000.000 de cabezas, "poco más o menos" 23 . Sumando a éstas las declaradas por los grandes ganaderos, los efectivos trashumantes en la primavera de 1780 podrían situarse entre 2.850 .000 y 2.900 .000 cabezas $^{24}$.

\subsection{Resumen general de $1780-81$}

Este recuento de ganado mesteño - el último del siglo XVIII y el único con un propósito estadístico - fue realizado a la salida del esquileo de 1780, es decir, entre los meses de mayo y junio de dicho año, y de él resultan 2.228.035 cabezas de ganado lanar trashumante ${ }^{25}$. El principal problema que plantea radica en que "la notoria esterilidad y falta de pastos" padecida durante la invernada anterior, había causado la muerte de muchas ovejas y reducido la cría del ejercicio a la mínima expresión. Los ganaderos cifraron las pérdidas en una cuarta parte de las cabezas ${ }^{26}$. ¿Exageraban, como era habitual? Dado que, de las 64 grandes explotaciones que declararon sus efectivos con motivo del repartimiento de 1776, 51 aparecen también en las relaciones correspondientes al resumen general de 1780-81, es posible hacer una evaluación del menoscabo que sufrió la cabaña a partir de una muestra significativa de ésta. El resultado es que sólo siete de esas 51 explotaciones tenían más ovejas en 1780 que en 1776; todas las demás experimentaron una merma, pero la caída media fue del 17,46 por 100 , de modo que, aun suponiendo que hubieran crecido algo entre 1776 y 1780, y que la disminución fuese sólo achacable a la mortandad de 1779-80, las pérdidas habría que situarlas más cerca —y por debajo- del 20 que del 25 por 100 .

\footnotetext{
22 AHN, Consejos, leg. 7.088.

23 AHN, Consejos, leg. 7.088; Memorial ajustado (1783), t. II, f. 158.

24 Según se excluyan, o no, al sumar las grandes cabañas, 55.831 cabezas pertenecientes a ganaderos avecindados en las sierras.

25 Memorial ajustado (1783), t. II, ff. 159v-162 y planos finales; AHN, Consejos, leg. 7.086.

26 Memorial ajustado (1783), t. II, f. 160. Conocemos las pérdidas de algunas cabañas concretas. La del monasterio de Guadalupe perdió un 20,84 por 100 de sus cabezas [Llopis (1982), p. 99]; la del marqués de San Felices y conde de Alcolea, un 25 por 100, y las de don Tomás de Echeverría y don Francisco de Rivera, más pequeñas, un 33 y un 50 por 100, respectivamente (AHN, Consejos, leg. 7.074).
} 
Si aceptamos una reducción general del 20 por 100, eso significaría que, a la salida del esquileo de 1779, la cabaña trashumante debía contar con 2.785 .000 cabezas, una cifra que coincide, casi exactamente, con la estimación hecha en marzo de 1780 por el Procurador de la Mesta. Teniendo en cuenta que el ejercicio 1778-79 tampoco había sido bueno ${ }^{27}$, es probable que hacia 1778 el número de cabezas rondara los 3.000.000, como indican los testimonios citados de ese período; una cifra que no volvería a alcanzarse, en el mejor de los casos, hasta bien entrada la segunda mitad de la década de los ochenta ${ }^{28}$. De todas formas, los datos de 1780, aunque es indudable que acusan la mortandad extraordinaria de la última invernada, también reflejan una tendencia de fondo, activada muchos años atrás, hacia la disminución de los efectivos trashumantes de las sierras y, en general, de las cabañas más pequeñas ${ }^{29}$.

\subsection{Las exportaciones de lana como indicador del tamaño de la cabaña trashumante a finales del siglo XVIII}

El vacío de información sobre el tamaño de la cabaña durante las dos últimas décadas del siglo puede cubrirse a partir de los datos sobre las exportaciones laneras. En principio, toda la lana exportada debía ser fina o entrefina, ya que estaba prohibida la extracción del país de lanas ordinarias; pero no todo el ganado que producía lana susceptible de exportación era trashumante. Los registros que la administración de la renta de lanas realizó entre 1770 y 1788 revelan la existencia -en media anual, para dicho período- de 8.590 .000 cabezas productoras de lana legalmente exportable $^{30}$. Puesto que, por esas mismas fechas, el número de cabezas trashumantes castellanas no pasaría, como máximo, de 3.500.000, el resto debían ser estantes, transterminantes o reses que trashumaban fuera de Castilla y al margen de la Mesta. De hecho, este ganado se concentraba en Extremadura, Andalucía y los reinos de Aragón y Valencia ${ }^{31}$; sin olvidar las sierras castellanas, donde el número de "merinas quedadas" fue aumentando a medida que muchos pequeños y medianos ganaderos abandonaban la trashumancia.

Respecto a la exportación de lana de calidades inferiores, una cosa eran las normas que la prohibían ${ }^{32}$ y otra muy distinta su cumplimiento. Uno de los portillos por

\footnotetext{
27 El monasterio de Guadalupe perdió el 12,25 por 100 de sus efectivos.

28 Se dudaba que "ningún ganadero se pu[diera] reponer de dichas pérdidas en seis u ocho años", (AHN, Consejos, leg. 7.074).

Pérez Romero (1996), p. 115, nota 58.

Franch (2000), pp. 76-78.

Sobre la procedencia de la lana exportable, véanse, por ejemplo, los aranceles de 1747, en García-Cuenca (1994), pp. 301-303.

32 Reales órdenes de 1699, 1723, 1751, 1772 y 1783 [Matilla (1950), pp. 18, 40, 115, 226 y 311].
} 
los que acabó colándose el fraude fue el de la lana entrefina, cuya extracción quedó expresamente autorizada al menos desde $1702^{33}$. Esta lana, que procedía, en principio, de ganado merino estante o transterminante radicado, sobre todo, en el piedemonte de las sierras del Sistema Central, era por las características de sus fibras — de mayor longitud que las de la fina- especialmente apta para la fabricación de paños estambrados, al tiempo que su hilado resultaba más barato y fácil de mecanizar que el de la lana de mayor calidad, lo que pudo hacer que su demanda aumentara durante la segunda mitad del siglo. No obstante, en 1782, la Sociedad de Amigos del País de Soria denunció que la falta de definición de la categoría de lana entrefina la había hecho "adaptable a todas clases de ellas", y se utilizaba para dar cobertura a la exportación de lanas ordinarias. Semejante fraude habría comenzado a raíz de las grandes mortandades de ganado de mediados de siglo, cuando "los compradores de lanas echaron mano de las churras menos bastas, ya para mezclarlas con las finas, ya para extraerlas solas" ${ }^{\prime 34}$. La Sociedad Económica de Segovia estimaba que la lana entrefina, como suerte intermedia entre la fina y la ordinaria, era fácilmente reconocible y que su exportación no debía obstaculizarse ${ }^{35}$, pero la opinión del intendente de esta provincia coincidía con la de la sociedad soriana: el de "entrefinas" era un "nombre inventado por los tratantes para sacar con este título las ordinarias de mayor calidad"36. Las alusiones que hace Larruga en las memorias de varias provincias a la problemática que planteaba la lana entrefina revelan que, en Castilla a finales del siglo XVIII, ésta era una categoría de uso tan extendido como impreciso ${ }^{37}$. Larruga también confirma que el "falsísimo nombre de lanas entrefinas" encubría en muchos casos la exportación de "lanas ordinarias ... sin distinción de clases y provincias", aunque el fraude podía adquirir tintes aún más descarados, ya que algunos mezclaban, sin más, lanas ordinarias con las finas y las llevaban a los "lavaderos de mejor nota, y de mayor concurso de lanas trashumantes", de donde salían, gracias a la complicidad de los factores, con la correspondiente guía hacia los puertos de embarque $^{38}$. En síntesis, aunque no es posible cuantificarla, la exportación ilegal de lana burda bajo la denominación de entrefina era una realidad innegable. El fraude parece que aumentó considerablemente a partir de 1789, cuando se relajaron los controles por parte de la administración de la renta de lanas ${ }^{39}$.

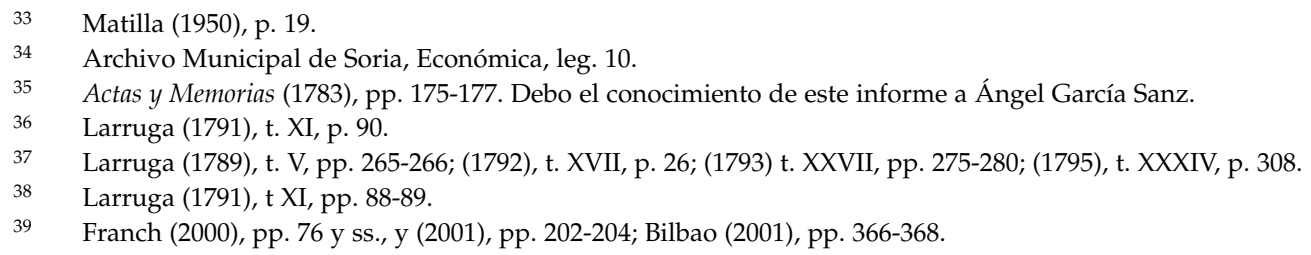




\section{CUADRO 2}

EXPORTACIONES APARENTES DE LANA PRODUCIDA POR GANADO QUE NO PARTICIPABA EN LA GRAN TRASHUMANCIA CASTELLANA $\left({ }^{*}\right)$

\begin{tabular}{lccc}
\hline Años & $\begin{array}{l}\text { Lana exportada procedente de ganado no trashumante o trashumante no mes- } \\
\text { teño, en porcentaje del total de exportaciones, según distintas estimaciones de } \\
\text { éstas }\end{array}$ & Franch \\
\hline \multicolumn{1}{l}{ Bilbao } & Phillips & \\
$\mathbf{1 7 0 7}$ & $0-8,0$ & 0 & $4,7-11,9$ \\
$\mathbf{1 7 5 0}$ & $14,6-21,8$ & $51,0-53,2$ & 58,9 \\
$\mathbf{1 7 7 9}$ & $40,7-43,4$ & $41,9-45,5$ & 56,4 \\
$\mathbf{1 7 8 0}$ & $53,1-56,0$ & 58,9 & \\
\hline (*) Los cálculos se han hecho para fechas con recuentos fiables de cabezas trashumantes, suponiendo que se expor- \\
taba toda la lana que éstas producían.
\end{tabular}

Fuentes: Bilbao (1998), Phillips y Phillips (1997), Franch (2000) y (2001), y los recuentos de ganado citados.

Para los diez años comprendidos entre 1787 y 1796 disponemos de datos sobre la cantidad de lana exportada, desagregados en función del origen geográfico de la misma, lo que, grosso modo, permite cuantificar la lana procedente de la Corona de Castilla y, a partir de ella, estimar los efectivos de la cabaña trashumante. Dichos datos tienen dos procedencias distintas: los de 1787 a 1793 los recoge Anes, y los de 1794 a 1796, Canga Argüelles ${ }^{40}$. Lo interesante es que unos y otros coinciden, casi exactamente, con las cifras correspondientes a dichos años en la serie de exportaciones publicada por Franch Benavent ${ }^{41}$. También los datos que Larruga proporciona de lana exportada desde las provincias de Ávila (1786, 1788 y 1790), Burgos (1788 y 1791), Extremadura (1786-93) y Segovia (1786-88) coinciden, casi milimétricamente, con los de Anes para las mismas procedencias y fechas ${ }^{42}$.

40 Anes (1970), cuadro entre pp. 318 y 319; Canga Argüelles (1840), p. 482. Los datos de Anes desagregan la lana exportada entre doce "provincias" de origen: Segovia, Soria, Cuenca, Ávila, Burgos, Ciudad Rodrigo, Extremadura, Valencia, Granada, Aragón, Cataluña y Reinos de Andalucía. Los de Canga Argüelles distinguen sólo siete procedencias: segoviana, castellana, extremeña, andaluza, zaragozana, de Albarracín y valenciana. Franch (2000), p. 79, y (2001), p. 208. Se trata de una serie de exportaciones anuales de lana (en arrobas) entre 1770 y 1796.

42 Larruga (1787-1800), t. XX, p. 31 (Ávila); t. XXVII, pp. 280 y 283 (Burgos); t. XXXVII, p. 286 (Extremadura) y t. XI, p. 88 (Segovia). En el caso de Cuenca, los datos de Larruga (t. XVIII, p.106) sólo coinciden con los de Anes para 1790. 
Finalmente, por lo que se refiere a Soria, la provincia desde la que más lana se exportaba, contamos para el período 1782-1808 con los datos de la recaudación de un arbitrio de medio real por cada arroba de lana que se extraía en limpio de la provincia con destino a la exportación ${ }^{43}$. Pues bien, las cantidades de lana que pueden calcularse a partir de ellos son casi las mismas que proporciona Anes para los años en que coinciden ambas series. Esta concordancia entre cinco fuentes distintas permite suponer que los datos de todas ellas tienen un origen común en los papeles de la administración de la renta de lanas. Por otro lado, si calculamos los derechos de aduana correspondientes a los años 1787, 1788 y 1789, aplicando a las cantidades de lana recogidas por Anes los aranceles entonces vigentes, las cifras resultantes coinciden, también con gran precisión, con las recaudaciones efectivas de dichos años ${ }^{44}$. Podemos, pues, concluir que los datos mencionados, relativos al decenio 1787-96 son altamente fiables.

En principio, de toda la lana exportada en dicho período, sólo la procedente de la Corona de Castilla podía ser fruto del ganado mesteño trashumante, a excepción de — si no toda, sí la mayor parte- la que tenía su origen en Extremadura y Andalucía; ya que, según Larruga, la lana fina extremeña no era de ganado trashumante sino "riveriega, que es la que produce el ganado de la provincia"45, y lo mismo podría decirse de la andaluza. Ciñéndonos, pues, a la lana exportada entre 1787 y 1796 desde territorios castellanos, excluyendo Extremadura y Andalucía, el número de cabezas necesarias para producirla sería, en media anual, algo menos de 3.250.000 ${ }^{46}$. Esta cifra marcaría el límite superior de los efectivos trashumantes durante el período final del siglo XVIII, un máximo que, probablemente, no se alcanzó en ningún momento, dado que habría que descontar las cabezas estantes de las áreas serranas productoras de lana entrefina. Además, dejando a un lado las de carácter "literario", las estimaciones coetáneas sobre la marcha de la cabaña apuntan cifras inferiores. Así, un informe encargado por el Banco de San Carlos calculaba que aquélla, "por un cálculo aproximado", contaría hacia 1794 con 3.000.000 de cabezas ${ }^{47}$. Otros testimonios, menos verosímiles, rebajan la cifra hasta $\operatorname{los} 2.000 .000^{48}$.

$43 \quad$ Rupérez (1987), p. 139.

44 Los datos de recaudación, en García-Cuenca (1995), pp.115-117. Este cálculo sólo puede hacerse para los tres años en que hay intersección entre las series de exportaciones que venimos manejando (1787-93) y la de la renta de lanas (1749-89).

45 Larruga (1795), t. XXXVII, p. 286; Melón (1992), pp. 27-28.

46 Esta cifra se ha calculado suponiendo que una cabeza producía anualmente 5 libras de lana en sucio, y que ésta perdía en torno al 60 por 100 de su peso al ser lavada; [García Sanz (1994a), p. 402].

47 Sobre el contexto en que se encargó este informe, Pérez Romero (2001).

48 Se trata de estimaciones de 1787 y 1795, es decir, una del comienzo y otra del final del período que aquí consideramos; [AHN, Estado, leg. 2.932/21 y Pérez Caballero (1796), p. 99]. 
Sin duda, el cálculo hecho a partir de las exportaciones de lana sobreestima el tamaño de la cabaña trashumante, porque mucha de la que se exportó durante las décadas finales del siglo y hasta la Guerra de Independencia procedía de ganado estante; fino o entrefino, pero estante ${ }^{49}$. A este respecto, tiene especial relevancia el aumento de la participación de la lana producida en Extremadura en las exportaciones totales. Entre 1749 y 1768 se exportaron 1.478 .939 arrobas de lana extremeña lavada ${ }^{50}$, lo que representó entre un 15,2 y un 17,5 por 100 de toda la lana exportada durante dicho período (según las estimaciones de los Phillips y de Bilbao, respectivamente). Sin embargo, entre 1787 y 1793, las exportaciones de lana extremeña alcanzaron las 752.458 arrobas, un 26,5 por 100 del total. En media anual, el aumento entre uno y otro período fue del 39,5 por 100 . Sería poco realista suponer que esta creciente orientación de la lana extremeña hacia la exportación no fue acompañada de un aumento del ganado, básicamente estante, que la producía. Aunque escasos, los datos de que disponemos apuntan en esta dirección. Así, el número de cabezas de ganado ovino en el partido de La Serena (Badajoz) pasó de unas 180.000 en 1755 a más de 240.000 en 1791 , es decir, creció un 33,3 por $100^{51}$. De forma parecida, entre 1752 y 1790, las cabezas de ovino estante experimentaron un notable crecimiento en algunos núcleos de la penillanura cacereña ${ }^{52}$. Esta expansión de la ganadería estante arroja luz sobre el conflicto que enfrentó al Honrado Concejo con la provincia de Extremadura, ya que entre los principales adversarios de los mesteños habría que contar a los productores de lana locales, cuyos beneficios debieron de crecer más que los de las cabañas trashumantes, si tenemos en cuenta la favorable evolución que experimentó la cotización de la lana que producían ${ }^{53}$ y que sus costes eran menores, al no incluir los asociados al desplazamiento del ganado.

\subsection{Recapitulación}

Si nos atenemos a las cifras de que disponemos basadas en recuentos o en estimaciones fiables, la trayectoria de la cabaña trashumante castellana durante el siglo XVIII podría resumirse del siguiente modo. Partiendo de unos 2.000.000 de cabezas en 1707, alcanzó, como máximo, 3.300.000 hacia mediados de la centuria $(1746$, c. 1752). A continuación, sufrió una importante merma como consecuencia de las mortandades de los años

Hernanz de Vargas (1993 [1814]), pp. 33-34.

Llopis (1982), p. 45, nota 100.

Si tomamos como punto de partida las cabezas existentes a comienzos del decenio de 1740, el aumento habría que rebajarlo a un 20 por 100, en un período, además, más largo; [Hernández (2002), pp. 85-89].

Melón (1989), pp. 176-177.

Melón (1989), pp. 183-185. 
CUADRO 3

EVOLUCIÓN CUANTITATIVA DE LA CABAÑA TRASHUMANTE CASTELLANA DURANTE

EL SIGLO XVIII(*)

\begin{tabular}{lcr}
\hline Fechas & Ovino trashumante (cabezas) & Índice (sobre medias) \\
\hline $\mathbf{1 7 0 7}$ & $2.000 .000-2.100 .000$ & 100 \\
$\mathbf{1 7 2 5 - 2 6}$ & $2.500 .000-2.600 .000$ & 124 \\
$\mathbf{1 7 4 6}$ & $3.144 .000-3.294 .000$ & 157 \\
$\mathbf{1 7 5 0 - 5 4}$ & $3.100 .000-3.250 .000$ & 155 \\
$\mathbf{1 7 6 5}$ & {$[3.500 .000]$} & {$[171]$} \\
$\mathbf{1 7 7 6 - 8 0}$ & {$[2.850 .000-2.900 .000]$} & {$[140]$} \\
$\mathbf{1 7 7 9 - 8 0}$ & $2.785 .000-2.970 .000$ & 140 \\
$\mathbf{1 7 8 0 - 8 1}$ & 2.228 .035 & 109 \\
$\mathbf{1 7 8 7 - 9 6}$ & {$[3.000 .000-3.240 .000]$} & {$[152]$} \\
$\mathbf{1 8 1 8}$ & 2.700 .000 & 132 \\
\hline
\end{tabular}

$\left(^{\star}\right)$ Entre corchetes las estimaciones menos sólidas.

Fuentes: las citadas más arriba; para 1818, Zapata (1820), pp. 39-40.

cincuenta (1750-51 y 1752-53), de cuyos efectos debió de tardar en reponerse casi un decenio. Resulta dudoso, sin embargo, que, además de recuperarse, la cabaña siguiese creciendo, como sugiere la estimación de 3.500 .000 cabezas para 1765. Ésta carece de respaldo documental suficiente para afianzar por sí sola la idea de que la expansión se prolongó durante el tercer cuarto del siglo. En sentido contrario, los diezmos de lana de varios núcleos segovianos parecen avalar la hipótesis de un estancamiento a partir de los años cincuenta ${ }^{54}$, y algunos testimonios de la época abundan en que a partir de mediados de siglo la cabaña entró — si no lo estaba ya - en una fase estacionaria e, incluso, de cierto retroceso, que culminaría con la crisis de 1779-80. Durante los dos decenios que siguieron a esta mortandad, la cabaña recuperó la cota anterior a la misma, sin que haya motivos para suponer un aumento significativo antes de la Guerra de la Independencia. Máxime cuando durante esos años, además de la escasez y el encarecimiento de los pastos y de otros insumos (trigo, sal), los productores de lana tuvieron que afrontar los problemas causados por la depreciación de los vales reales y las guerras contra Inglaterra y Francia, con sus secuelas de interrupciones del comercio exterior, perturbaciones en los sistemas de pagos y en los circuitos internacionales de crédito ligados al comercio lanero, volatilidad cambiaria y crisis generalizadas de liquidez ${ }^{55}$.

$54 \quad$ García Sanz (1994b), pp. 139-140.

55 A algunos de estos factores, que "ha[bía]n minorado considerablemente la ganadería" trashumante, se hace referencia en el preámbulo a una provisión del Consejo, de 16 mayo 1799; [Brieva (1828), p. 295]. 


\section{La creciente dificultad de acceso a los pastos como principal límite al aumento de la cabaña}

El tamaño de la cabaña trashumante se estabilizó, paradójicamente, durante "uno de los períodos de resultados más brillantes de los productores de lana fina" $(1763-85)^{56}$, en cuyo transcurso las exportaciones laneras alcanzaron sus máximos seculares. $\mathrm{Ni}$ la fuerte demanda externa de lana, ni la elevada rentabilidad de las explotaciones parecen haber sido capaces de impulsar el crecimiento de la cabaña. ¿Por qué?

A comienzos de la década de 1770, algunos atribuían el estancamiento a las grandes mortandades de mediados de siglo ${ }^{57}$. Es indudable que éstas y otros episodios semejantes, como los de 1726-27 y 1779-80, provocaron sendos e importantes retrocesos; pero, por lo que sabemos acerca del potencial reproductivo de los rebaños, dichas pérdidas pudieron reponerse en todos los casos con relativa rapidez. No cabe, pues, atribuir a estas mortandades cíclicas efectos duraderos sobre el número de cabezas (más importantes debieron de ser sus repercusiones coyunturales en los mercados laneros y de pastos).

Todo apunta a que la razón fundamental por la que se estancó el tamaño de la cabaña fue otra: los ganaderos ya no podían conseguir, ni en los agostaderos ni en los invernaderos, nuevos pastizales con los que sustentar más ovejas trashumantes. Entiéndase bien, lo que bloqueó el crecimiento no fue tanto el encarecimiento de las hierbas cuanto la imposibilidad de adquirir más ${ }^{58}$. Aunque, durante el siglo XVIII, el precio de los pastos aumentó (si bien aún no está claro en qué medida) y ello empujó al alza los costes de las explotaciones trashumantes, muy probablemente, lo hizo más en términos absolutos que relativos. Si, como apuntan algunos datos, los precios de la lana crecieron más deprisa que los de las hierbas $-\mathrm{O}$, al menos, no se quedaron rezagados en relación con éstos-, es muy posible que la repercusión del importe de los pastos necesarios para producir una arroba de lana en sucio sobre el ingreso bruto que ésta generaba tendiese a disminuir —o se mantuviera estable - durante la centuria.

La falta de pastos puede ser vista $-\mathrm{y}$, de hecho, lo ha sido- como una consecuencia de la ampliación de la superficie cultivada que se produjo durante el siglo XVIII. Esta explicación presupone que la expansión de los labrantíos implicó una importante transferencia de suelo desde la dedicación ganadera a la agrícola, mediante la roturación de pastizales. Sin embargo, de los cambios que se produjeron en la estructura de precios relativos no cabe deducir efectos reasignadores

\footnotetext{
$56 \quad$ Llopis (1982), p. 43.

57 Carta de Ynstrucción Práctica de un ganadero..., f. 178r.

58 Esta idea no es nueva. Ha sido apuntada por autores que han abordado el tema desde distintas perspectivas: Llopis (1982), pp. 43, 51; Pérez Romero (1996), pp. 110-111; Hernández (2002), p. 91.
} 
paralelos e inmediatos sobre el factor tierra. En la actualidad, tiende a considerarse que el impulso roturador que se encuentra en la base del crecimiento agrario del siglo XVIII fue más débil de lo que habrían permitido las restricciones medioambientales y técnicas, debido a la actuación de grupos sociales e instituciones con intereses contrarios a los rompimientos y con poder suficiente para contenerlos ${ }^{59}$. Por otro lado, las roturaciones no siempre afectaban negativamente a los rebaños trashumantes. Las que se realizaban en terrenos montuosos, lejos de disminuir, podían aumentar los pastos útiles, al habilitar para el ganado, al menos en los años en que la tierra no se sembraba, espacios antes inaccesibles ${ }^{60}$. En cualquier caso, el "frente antirroturador", del que formaban parte los ganaderos trashumantes y la Mesta, consiguió que el marco legal fuera poco propicio a la puesta en cultivo de áreas de pasto, salvo por la trabajosa vía de la obtención de facultades pueblo a pueblo. Es cierto que los privilegios mesteños, y disposiciones como el decreto de 30 de diciembre de 1748, no lograron impedir las roturaciones arbitrarias, pero sí frenaron su expansión. Al ser ilegales y, por ende, inseguras y precarias, sólo allí donde contaban con la aquiescencia y la complicidad de las oligarquías locales podían alcanzar cierta amplitud. Estos bloqueos sociales e institucionales explican, en buena medida, que el aumento de la producción agraria no fuera especialmente intenso en las regiones donde agostaban o invernaban los rebaños trashumantes ${ }^{61}$, lo que permite cuestionar que antes de finales de siglo se produjera una transferencia significativa hacia el cultivo de suelo ocupado previamente por los rebaños de merinas. Más bien parece que ocurrió lo contrario durante la primera mitad de la centuria cuando, en Extremadura, dehesas hasta entonces de pasto y labor se redujeron a dehesas de puro pasto ${ }^{62}$.

El principal desafío externo que tuvieron que afrontar los mesteños quizá no provino tanto de los roturadores cuanto de los ganaderos estantes. Es posible que a comienzos de siglo, "diputados de los pueblos y de particulares" extremeños acudiesen "a los puertos por donde entra[ba]n ... los ganados transumantes a solicitar que sus dueños o mayorales tomasen las dehesas, por no tener ganados para aprovecharlas" por sí mismos ${ }^{63}$. Pero los autos acordados de 1702, 1703 y 1706 revelan tempranas tensiones entre los ganaderos trashumantes y los dueños de las dehesas

59 Llopis (2002), pp. 128-129, y (2003); Sebastián (2004), pp. 148-155.

60 Con las roturaciones aumentaban también rastrojeras y barbecheras, al tiempo que la producción de cereales-pienso, todo lo cual favorecía al ganado estante.

61 Marcos (2000), pp. 608-612, 614-623. En las sierras - y también en los extremos- había pocas alternativas sostenibles a la dedicación pastoril de amplias superficies.

62 Sánchez Salazar (1988), pp. 83-87; Llopis (1989), p. 277.

63 Es lo que cuenta el ganadero soriano don Bernardo Pérez Caballero en su Instrucción de hecho manifestando las causas de la decadencia de Extremadura y por las que no es más opulenta, escrita hacia 1768; (AHN, Sección Nobleza, Osuna, cartas, leg. 580). 
de invernadero, en torno al precio de las hierbas, los plazos para el pago de los arrendamientos y el respeto de la posesión ${ }^{64}$. No obstante, las medidas dictadas en dichos autos, unidas a la escasez relativa de ganado local tras la Guerra de Sucesión, permitieron a los trashumantes aumentar los pastizales a disposición de sus rebaños al mismo ritmo que éstos crecían. No es de extrañar que, hacia 1720, el Honrado Concejo afirmara que "nunca [antes] había conseguido el sosiego en que se h[abía]an visto sus individuos" durante los tres lustros siguientes a $1702^{65}$. Pero, a medida que se recuperaba la cabaña extremeña, sus dificultades para arrendar nuevos pastos se fueron acrecentando. En 1718, ya empezaron "a experimentar una notable novedad en las yerbas, así de comunidades como de particulares" en todas las áreas de invernadero: no sólo se les pedían precios más altos ${ }^{66}$, sino que, como denunciaron hacia 1724, en las subastas se tendía a postergar a los ganaderos trashumantes en beneficio de los riberiegos ("aunque fuese a precios muy inferiores") e incluso de labradores ${ }^{67}$. La percepción del peligro que suponía esta competencia llevó, a comienzos de los años cuarenta, al Honrado Concejo a condicionar la expedición de cartas de hermandad en favor de ganaderos riberiegos y estantes a que éstas no redundaran en perjuicio de las "posesiones" de los auténticos trashumantes ${ }^{68}$. Por entonces, hacerse con nuevos pastos era ya una empresa difícil, incluso en los agostaderos.

Cuando se habla de escasez y encarecimiento de pastos, la atención se dirige a las zonas de invernadero. Es lógico porque las hierbas meridionales constituían el principal coste de las explotaciones trashumantes, porque allí pasaba el ganado la mayor parte del año y allí hubo de librar la Mesta una encarnizada batalla en defensa de sus privilegios. Pero la escasez no fue menos acusada en los agostaderos; es más, en términos relativos, quizá fue mayor y anterior en éstos, con la única excepción de los grandes pastizales asturleoneses. De hecho, hay testimonios que apuntan a una temprana saturación de los pastos de verano en el sistema Ibérico ${ }^{69}$. Por las cuentas de la cabaña de Guadalupe, sabemos que el precio de los pastos leoneses experimentó un precoz movimiento ascendente entre 1709 y 1739, y que, luego, se

64 Tomo tercero de autos acordados (1982 [1745]), pp. 398-401.

65 AHN, Mesta, leg. 247/23. El auto-acordado de 1702 estableció precios máximos por cabeza en los invernaderos. Cabe la posibilidad de que los arrendadores de hierbas mejoraran su renta a costa de incrementar la carga ganadera de las dehesas, lo que permitiría explicar, en parte, la paradoja de que durante algún tiempo la escasez de pastos fuera compatible con una cierta estabilidad de su coste por cabeza. En contrapartida, habría aumentado la vulnerabilidad de los rebaños a los años de sequía y hierbas escasas. El Consejo requirió repetidamente a los dueños de dehesas para que ajustasen sus precios a lo establecido en el auto-acordado de 1702. Así lo hizo, por ejemplo, mediante real provisión, en 1722; (AHN, Mesta, leg. 247/26). AHN, Mesta, leg. 247/26, y provisión del Consejo de 17 de agosto de 1726, para que en las dehesas vacantes y que estaban por arrendar se admitiesen las posturas de los mesteños, (AHN, Mesta, leg. 247/38). Acuerdos de 30 de abril de 1741 y 5 de octubre de 1743; [Brieva (1828), p. 66].

Pérez Romero (1995), p. 248. 
mantuvo relativamente estable hasta 1779 , para elevarse bruscamente en los años siguientes, hasta comienzos del siglo $\mathrm{XIX}^{70}$. Mientras que el índice del coste por cabeza de las hierbas invernales pasó de 100, en el bienio 1709-10, a 124,4, en el de 1782-83, el de las estivales creció, en el mismo período, de 100 a 205,771.

La progresiva escasez de pastos desató una amplia, ubicua y multiforme conflictividad por su control, que no quedó circunscrita a la lucha entre estantes (ganaderos y, también, labradores interesados en aumentar la dotación de ganado local para mejorar el abonado de sus tierras) y trashumantes, sino que acabó enfrentando a unos mesteños con otros. En esta pugna intervino la Corona, primero de forma indirecta, a través de la venta de dehesas de las órdenes militares y de baldíos - aunque la de estos últimos acabó siendo anulada- y, más tarde, mediante cambios legislativos en materia de acceso a los pastos concejiles. El resultado fue una redistribución social - y, en cierto modo, espacial- de los recursos sin apenas reasignación productiva.

Las enajenaciones realizadas por la Corona, aunque su objetivo primordial fuera recaudatorio, tuvieron importantes efectos redistributivos. A este respecto, resulta paradigmático el caso de la venta de la dehesa de La Serena. Por un lado, provocó el desalojo de la misma de más de 90.000 cabezas pertenecientes a ganaderos serranos, en beneficio de los potentados madrileños; por otro, los ganaderos locales también sacaron partido de la operación al consolidar su derecho sobre la tercera parte de las hierbas de la dehesa. Mauro Hernández concluye que el principal estímulo para las compras fue el de hacerse con el control de unos pastos cada vez más escasos ${ }^{72}$.

En cuanto a los cambios en la normativa sobre pastos concejiles ${ }^{73}$, la disposición de mayor trascendencia fue la real provisión de 3 de noviembre de 1767, que estableció en Extremadura un sistema de tasa y reparto "entre los vecinos de cada pueblo" como forma de acceso a los pastos de propios y arbitrios ${ }^{74}$. De éstos, sólo los sobrantes podrían ser adjudicados "a los forasteros", dando preferencia "a los de los pueblos que fuesen comuneros o cercanos, y en su defecto a los más inmediatos". Aunque nada decía expresamente al respecto, esta provisión fue interpretada como una derogación del derecho de posesión sobre todos los pastos concejiles. La prueba es que, entre finales de 1767 y comienzos de 1768, se produjo en Extremadura una oleada de autos de desahucio, dirigidos a expulsar a los ganaderos trashumantes de las dehesas de propios y de los pastos sobrantes de las boyales.

\footnotetext{
$70 \quad$ Llopis (1982), pp. 23, 50-51 y 55.

71 Los datos para este cálculo en Llopis (1982), pp. 91-92.

72 Hernández (2002), pp. 90-91.

73 Dichos cambios se iniciaron con la providencia del Consejo de 20 de abril de 1761, que introdujo una primera, aunque muy leve, restricción de carácter general a la posesión mesteña.

74 AHN, Consejos, libro 1.535, ff. 418-420.
} 
Cuando otra provisión de 18 de marzo de $1768^{75}$ hizo extensivo el contenido de la de 3 de noviembre de 1767 a todo el reino, los desahucios se generalizaron tanto en los invernaderos como en las sierras, donde muchos pueblos trataron de recuperar el control de las rastrojeras y de otros pastos concejiles que, desde finales del siglo XVI, venían arrendando durante el verano a los ganaderos trashumantes y sobre los que éstos alegaban posesión ${ }^{76}$.

Los ganaderos trashumantes protestaron; pero no lo hicieron presentando un frente unido. En la primavera de 1768 llegaron tres recursos distintos al Consejo de Castilla. Uno del Presidente del Honrado Concejo, otro de los ganaderos de Madrid y un tercero de las cuadrillas serranas ${ }^{77}$. El primero se limitaba a pedir que los derechos de preferencia y tanteo que se reconocían a vecinos, comuneros e "inmediatos", sólo pudieran ejercerse en beneficio del ganado estante o riberiego, pero no del trashumante. Se quería evitar que un mesteño despojase a otro de sus pastos alegando preferencia vecinal o comunera, con el argumento de que, en lo referente al pastoreo de sus rebaños, los ganaderos trashumantes "gozaba[n] de una vecindad común, indefinida y general en todo el Reino". Desconocemos cómo plantearon el asunto los madrileños. Pero los serranos fueron más allá, al pedir la anulación de los desahucios y que las nuevas provisiones se aplicaran respetando estrictamente los privilegios mesteños de posesión y tasa; lo contrario - alegaban-supondría para ellos la ruina, "porque, no siendo posible hallar otros pastos, se verían en la precisión de dejarlos morir o venderlos [sus rebaños] a los moradores de tierras llanas y dueños de dehesas". Resulta evidente que el problema de fondo era la escasez de hierbas y, también, que los pequeños y medianos ganaderos de las sierras habían sido los más perjudicados por la enajenación de dehesas de las órdenes, por la preferencia vecinal establecida en 1761 para acceder a las "arbitradas con facultad real", por la conversión de algunos dueños de dehesas en ganaderos (lo que implicaba el desalojo de los posesionarios), así como por el estrechamiento de los baldíos a causa de las roturaciones.

A comienzos de septiembre de 1768 , cuando ya era inminente la salida de los rebaños "cañada abajo", el Consejo determinó que durante la próxima invernada aquéllos fueran acomodados "en los sobrantes", pero dejando claro que a partir del año siguiente deberían buscarse otros pastos. Los ganaderos intentaron detener o atemperar el proceso, pero los desahucios continuaron adelante, incluso en aquellos casos en que, antes de que se promulgaran las nuevas disposiciones, habían pagado por anticipado el importe de varios años de arrendamiento ${ }^{78}$.

\footnotetext{
75 AHN, Consejos, libro 1.535, f. 578.

76 Pérez Romero (1995), pp. 277-290, y (1996), pp. 105-112.

77 AHN, Consejos, leg. 7.087.

$78 \quad$ AHN, Consejos, leg. 7.087.
} 
Finalmente, la real provisión de 26 de mayo de $1770^{79}$ confirmó un sistema de tasa y reparto de los pastos concejiles entre los vecinos ${ }^{80}$, complementado por otro de subasta, "sobre el precio de la tasa", para los sobrantes. A estas subastas podían concurrir los forasteros, sin que cupiera, una vez adjudicados los pastos "al mayor postor", admitir "nueva tasa, tanteo ni preferencia, por privilegiado que sea el ganado". Así, la posesión había dejado de ser aplicable, primero de facto y luego de pleno derecho, a los pastos de propios y arbitrios.

El impacto de estas disposiciones fue importante. En 1768, los propietarios de 339 explotaciones, en su mayoría pequeños y medianos ganaderos de las actuales provincias de Soria y La Rioja, más algunos de las de Burgos, Cuenca y Guadalajara, manifestaron que dos tercios de las cabezas que poseían (y que, en total, equivalían al 10 por 100 de la cabaña trashumante castellana) se encontrarían en precario a partir del año siguiente: 87.463 ya carecían de pastos seguros e invernaban en calidad de acogidas o bajaban "a sus aventuras", en tanto que otras 254.500, con posesión en pastos concejiles, corrían el riesgo de ser desahuciadas de forma inminente. Con toda seguridad, había muchos más ganaderos en idéntica situación. Y sus temores se materializaron. Sabemos que desde 1769 se excluyó a los ganaderos trashumantes de los propios de la ciudad de Mérida, ejemplo que siguieron los pueblos del partido; y que lo mismo ocurrió en Trujillo y en el partido de Llerena. ${ }^{81}$ Probablemente, esa fue la tónica en toda Extremadura y en las demás áreas de invernada. Los serranos, que, de nuevo, resultaron los más afectados, lograron en 1784 , cuando ya estaban sumidos en una profunda crisis, que se les reconociera preferencia frente a los "comuneros" en la adjudicación de algunos pastos que no precisasen los "vecinos". Era una mínima mejora que, además de tardía, debió de resultar poco efectiva, pues la disposición tuvo que ser reiterada cuatro años después $^{82}$.

79 Novísima Recopilación, ley XVII, título XXV, libro VII.

80 Un real decreto de 14 de enero de 1771 estableció que el reparto debía hacerse "entre vecinos y comuneros"; (Novísima Recopilación, ley XVII, título XXV, libro VII, nota 15).

81 Fuentes (1986), p. 69; Llopis (1982), p. 40, n. 91; Linares (1995), pp. 105-107.

82 Novísima Recopilación, notas 16 y 17 a la ley XVII, título XXV, libro VII. Muchos ganaderos sorianos hacían mención expresa de ella en los poderes notariales que otorgaban a sus mayorales para, entre otros cometidos, arrendar pastos en los invernaderos, lo que constituye un síntoma de la frecuencia con que debían verse obligados a reclamar su aplicación ante los tribunales. 
CUADRO 4

PASTOS DE INVERNADERO DE 339 EXPLOTACIONES

TRASHUMANTES DE LAS SIERRAS (c. 1768)

\begin{tabular}{|c|c|c|c|c|c|c|}
\hline \multirow{2}{*}{\multicolumn{3}{|c|}{ Explotaciones }} & \multicolumn{4}{|c|}{ Cabezas (porcentajes)( $\left.{ }^{*}\right)$} \\
\hline & & & \multicolumn{2}{|c|}{ Con posesión } & \multicolumn{2}{|c|}{ Sin posesión } \\
\hline $\begin{array}{c}\text { Tamaño } \\
\text { (cabezas) }\end{array}$ & Número & Cabezas & $\begin{array}{l}\text { En pastos } \\
\text { particulares }\end{array}$ & $\begin{array}{l}\text { En pastos } \\
\text { concejiles }\end{array}$ & Acogidas & $\begin{array}{c}\text { Sin } \\
\text { pastos }\end{array}$ \\
\hline$>3.000$ & 54 & 313.671 & 39,48 & 47,60 & 1,54 & 11,38 \\
\hline $1.001-3.000$ & 77 & 140.187 & 28,60 & 54,45 & 0,32 & 16,63 \\
\hline $251-1.000$ & 90 & 53.222 & 21,74 & 49,01 & 0,53 & 28,72 \\
\hline$<250$ & 118 & 11.628 & 12,85 & 23,17 & 19,09 & 44,88 \\
\hline Totales y medias & 339 & 518.760 & 34,08 & 49,06 & 1,50 & 15,36 \\
\hline
\end{tabular}

Fuente: AHN, Consejos, leg. 7.087.

La posesión sufrió otro embate con la real cédula de 8 de septiembre de 1789 , por la que se aprobaba una "nueva ordenanza para el régimen y gobierno de la cría de caballos de raza", que supeditaba la aplicación de los privilegios de la Mesta, especialmente en terrenos concejiles y baldíos, a las necesidades del "ganado yeguar de casta y raza" ${ }^{\prime 83}$. Finalmente, el real decreto de 28 de abril de 1793, al permitir y alentar la roturación de muchas dehesas de particulares, resultó especialmente lesivo para los intereses de los ganaderos trashumantes, que vieron disminuir aún más la superficie de pastos a su disposición en la provincia de Extremadura ${ }^{84}$.

La transferencia de pastos desde los trashumantes hacia los ganaderos locales, al acentuar la escasez de hierbas para los primeros, agravó la conflictividad por el acceso a las mismas en el seno de la corporación mesteña, comprometiendo de forma irreversible la solidaridad entre los "hermanos". Las diferencias llegaron a afectar a cuestiones tan esenciales como la actitud ante el privilegio de posesión, que, si bien experimentó un recorte en su ámbito de aplicación, en lo sustancial se mantuvo vigente y conservó su efectividad. De no haber sido así, resultaría difícil de explicar

\footnotetext{
83 Novísima Recopilación, ley XI, título XXIX, libro VII. En 1792, otra real cédula, aclaratoria de ésta, trató de conciliar la preferencia concedida al ganado caballar con el fomento de la ganadería trashumante. 
que los ilustrados dedicaran tantas energías a combatirlo en el plano doctrinal y que el ganado con posesión fuera más caro que el que carecía de ella. No obstante, los mesteños tuvieron que recurrir cada vez con mayor frecuencia $-\mathrm{y}$, probablemente, con menor éxito- a los tribunales para defender la aplicación del privilegio conforme a las normas del Quaderno, lo que incrementó sus costes de transacción y, lo que era peor, el nivel de incertidumbre que tenían que asumir, porque si sufrían un desahucio sin margen suficiente para encontrar pastos alternativos y se retrasaba el amparo judicial, los daños podían ser irreparables.

Los más interesados en la subsistencia del privilegio eran los ganaderos más cómodamente instalados en el statu quo, es decir, los que ya tenían pastos y no necesitaban más. Pero, en un contexto de creciente escasez de hierbas, la posesión constituía una importante barrera de entrada al negocio lanero para quienes querían crear nuevas cabañas y un obstáculo para la ampliación de las existentes, no sólo porque inmovilizaba las hierbas ya arrendadas sino, también, porque podía dificultar la contratación de las aún vacantes, al preferir sus dueños como arrendatarios a ganaderos estantes que no limitaran sus derechos de propiedad. Ningún ganadero trashumante podía oponerse abiertamente a una norma de la que todos, en mayor o menor medida, se beneficiaban o esperaban hacerlo. Pero algunos, sobre todo los poderosos ganaderos madrileños y de tierras llanas, con tal de hacerse un hueco o de mejorar sus posiciones en el negocio lanero, se mostraron dispuestos a aceptar una cierta erosión del derecho, como la que se derivaba de la aplicación de la nueva legislación sobre pastos concejiles, o la que ellos mismos causaban al practicar el acaparamiento - vía compra o arriendo - y la reventa de pastos, forzando hasta la adulteración las normas que regulaban la posesión. En general, los grandes ganaderos, más preocupados por la escasez que por el precio de los pastos, tendieron a contemporizar y llegar a acuerdos con los dueños de las dehesas y las oligarquías locales, lo que implicaba asumir, en la práctica, límites al ejercicio de la posesión y cierta ampliación de los mecanismos de mercado en la asignación de las hierbas; además, en la medida en que recurrieron a la compra de pastos para garantizarse el acceso a los mismos, la posesión perdió interés para ellos. Por el contrario, los ganaderos más modestos, tan preocupados por el precio como por la escasez, no sólo pusieron más empeño en una defensa cerrada e intransigente del privilegio, sino que reclamaron un mayor grado de intervencionismo y de regulación por parte de la Corona, llegando a pedir que se limitase el tamaño de las cabañas y que los pastos disponibles se repartieran equitativamente entre todas las existentes ${ }^{85}$. Además, para los grandes ganaderos, el acceso a los pastos invernales se veía facilitado por su influencia y sus relaciones sociales y políticas, su capacidad económica y su flexibilidad negociadora. 
Por otro lado, no fueron los más perjudicados por las reformas legales. No cabe duda, por ejemplo, de que el cambio en las normas de acceso a los pastos concejiles perjudicó a los ganaderos modestos, pero al aliviar la necesidad de pastos de los estantes y de los labradores, pudo relajar la presión sobre las demás cabañas -las mayores, que arrendaban sobre todo pastos de particulares - en las regiones afectadas. Lo esencial es que estas diferencias resquebrajaron la solidaridad interna y contribuyeron al debilitamiento de la Mesta, que se sumió en una crisis institucional y política que ya no sería capaz de superar.

\section{Cambios en la distribución geográfica de la propiedad del ganado trashumante}

Uno de los principales cambios que experimentó la localización de la propiedad del ganado trashumante en el transcurso del siglo XVIII fue el de la creciente importancia, en términos absolutos y relativos, de las cabañas pertenecientes a los ganaderos residentes en la villa y corte. No obstante, este fenómeno, conocido y subrayado por muchos autores, no debiera exagerarse, ya que, durante todo el siglo, más de dos tercios de la cabaña siguieron en manos de ganaderos avecindados en las sierras ${ }^{86}$.

La ganadería serrana no siguió la misma trayectoria en todos los casos. Durante la primera mitad de la centuria, el crecimiento parece haber sido general, pero desigual. La zona más pujante fue el Sistema Ibérico, donde el número de cabezas aumentó cerca de un 50 por 100. En el Sistema Central, el crecimiento fue mucho menor o quizá nulo ${ }^{87}$, aunque los fluidos intercambios que esta área mantenía con la capital dificultan el análisis de su evolución. Finalmente, por lo que se refiere a los montes asturleoneses, la inmensa mayoría de los propietarios locales eran mayorales o pastores de otras cabañas y las variaciones en su número y, sobre todo, en la importancia de sus rebaños son sólo achacables a la desigual precisión con que los registraron las distintas fuentes. Durante el tercer cuarto del siglo $-\mathrm{y}$ la tendencia de este período seguramente se acentuó durante el resto de la centuria- se produjo un pequeño retroceso en el Sistema Ibérico occidental (las actuales provincias de Burgos, La Rioja y Soria), en tanto que en el Sistema Ibérico oriental (Cuenca y Guadalajara), el número de cabezas retornó a las cotas de comienzos de siglo, y en el Sistema Central descendió aún más.

\footnotetext{
86 Aplicando un criterio puramente geográfico, considero como tales los monasterios de El Paular y El Escorial.

87 Este sería el caso si admitimos que la mayor parte del ganado que pastaba "fuera del término" en los pueblos de la actual provincia de Salamanca era sólo transterminante.
} 
Estas marcadas diferencias en la evolución de las distintas áreas serranas pueden explicarse por tres factores principales. Primero, por la desigual cabida de sus respectivos agostaderos, teniendo en cuenta tanto las hierbas de los baldíos como las dehesas y los montes concejiles, los entrepanes, los barbechos y las rastrojeras. Segundo, por la distinta capacidad de los ganaderos locales para preservar o ampliar los pastizales a disposición de sus rebaños (resguardando los baldíos de roturaciones y acotamientos o incorporando a los agostaderos espacios propios de las comunidades campesinas), así como para controlar los precios de los pastos y excluir de su disfrute a los ganaderos foráneos. Y, tercero, por el dispar grado de concentración de la propiedad de los rebaños, en cuanto de él dependía la existencia, o no, de una oligarquía de ganaderos trashumantes firmemente instalada en las instituciones de poder local y en disposición de afrontar con éxito la defensa de sus intereses; pero también porque se daba cierta correlación positiva entre el tamaño de las cabañas, su nivel de solvencia y/o la facilidad con que podían acceder al crédito.

Si los ganaderos del partido mesteño de Soria sortearon mejor que otros las dificultades que tuvieron que afrontar todos los serranos ello se debió, en buena medida, a que estos factores geográficos, sociales e institucionales operaron a su favor. Los amplios agostaderos sorianos — que los ganaderos locales utilizaban de forma gratuita o a muy bajo precio- permanecieron completamente cerrados a los mesteños de otras procedencias (lo que, por otro lado, retenía a los ganaderos en sus lugares de residencia, puesto que la pérdida de la vecindad implicaba la del acceso a los pastos de verano). Además, en la región soriana, en medio de un vivo conflicto por la redistribución interna de los pastos de verano, se intensificó la concentración de la propiedad del ganado, lo que fortaleció su capacidad de resistencia a costa de una mayor oligarquización. La situación de los ganaderos del área oriental del Sistema Ibérico y del Sistema Central en el transcurso del siglo XVIII nos es, de momento, peor conocida; pero, además de disponer de menos pastos que los sorianos, es probable que sus regímenes de aprovechamiento les protegieran menos de las intrusiones de ganaderos extraños (al tiempo que facilitaban a los autóctonos el traslado de su residencia fuera del área serrana).

Por lo que respecta a los ganaderos "dispersos" avecindados en núcleos urbanos de tierras llanas, es seguro que su número aumentó durante la primera mitad del Setecientos, en tanto que su disminución en los veinticinco años siguientes puede que sea sólo aparente. Es probable que este grupo esté sobrevalorado en las cifras catastrales (al incluir a no trashumantes, andaluces y castellano-manchegos sobre todo) e infravalorado en el recuento de 1780; aunque esto último no es del todo seguro, ya que caben explicaciones alternativas, como que algunos ganaderos de tierras llanas se hubieran integrado en las cuadrillas mesteñas o hubieran trasladado su residencia a la capital del reino. 


\section{CUADRO 5}

EVOLUCIÓN DE LA DISTRIBUCIÓN GEOGRÁFICA DE LA PROPIEDAD DEL GANADO TRASHUMANTE

\begin{tabular}{|c|c|c|c|c|c|c|c|c|}
\hline \multirow{2}{*}{ Áreas (*) } & \multicolumn{2}{|c|}{1707} & \multicolumn{3}{|c|}{ c. 1752} & \multirow{2}{*}{$\frac{\text { c.1776 }}{\text { Cabezas }}$} & \multicolumn{2}{|c|}{1780} \\
\hline & Cabezas & $\%$ & Cabezas & $\%$ & $\%\left(^{\star \star}\right)$ & & Cabezas & $\%$ \\
\hline $\begin{array}{l}\text { Sistema Ibérico } \\
\text { occidental }\end{array}$ & 816.431 & 38,57 & 1.201 .230 & 36,98 & 38,87 & & 879.313 & 38,47 \\
\hline $\begin{array}{l}\text { Sistema Ibérico } \\
\text { oriental }\end{array}$ & 293.774 & 13,88 & 443.260 & 13,65 & 14,34 & & 241.338 & 10,83 \\
\hline Sistema Central & 559.004 & 26,41 & 577.169 & 17,77 & 18,68 & & 380.828 & 17,09 \\
\hline Montes astur-leoneses & 4.129 & 0,20 & 45.209 & 1,39 & 1,46 & & 82.160 & 3,69 \\
\hline Total sierras & 1.673 .338 & 79,06 & 2.266 .868 & 69,79 & 73,35 & & 1.583 .639 & 71,08 \\
\hline Madrid (capital) & 255.901 & 12,09 & 499.991 & 15,39 & 16,18 & 594.877 & 561.847 & 25,22 \\
\hline Extremadura & 39.520 & 1,87 & 56.167 & 1,73 & 1,82 & & 51.084 & 2,29 \\
\hline $\begin{array}{l}\text { Resto de tierras } \\
\text { llanas }\end{array}$ & 147.753 & 6,98 & 424.882 & 13,08 & 8,65 & & 31.465 & 1,41 \\
\hline Total tierras llanas & 443.171 & 20,94 & 981.040 & 30,21 & 26,65 & & 644.396 & 28,92 \\
\hline Total & 2.116 .512 & & 3.247 .908 & & & & 2.228 .035 & \\
\hline
\end{tabular}

(*) Provincias actuales que comprenden cada una de las áreas. Sistema lbérico occidental: Burgos, La Rioja y Soria; Sistema Ibérico oriental: Cuenca y Guadalajara; Sistema Central: Ávila, Salamanca, Segovia y Madrid provincia; Montes astur-leoneses: Asturias, León, Palencia y Zamora.

$\left.{ }^{(*}\right)$ Sin tener en cuenta el ganado catastrado en las provincias andaluzas.

Fuentes: las citadas a lo largo del texto.

\section{Conclusiones y consideraciones finales}

La cabaña trashumante castellana creció vigorosamente durante la primera mitad del siglo XVIII, hasta alcanzar un tamaño algo superior al máximo del siglo XVI. Pero, en un momento difícil de determinar, entre mediados de la década de los cincuenta y la de los sesenta, se estancó, oscilando a partir de entonces en torno a los 3.000.000 de cabezas hasta la Guerra de la Independencia. 
El principal factor limitativo del crecimiento de la cabaña trashumante no parece que fuera la caída de la demanda exterior de lana, ni la falta de rentabilidad de las explotaciones, ni tampoco las recurrentes mortandades de ganado, sino la saturación de los pastos disponibles, tanto en los invernaderos como en los agostaderos. No se trató, en principio, de un problema de precio - aunque acabara siéndolo para muchos ganaderos serranos-, sino de escasez, acentuada por la competencia de la ganadería estante y, en menor medida, por una presión roturadora que no debió de alcanzar proporciones importantes hasta los últimos años del siglo.

La rigidez y la insuficiencia de la oferta de lana fina producida en régimen de trashumancia que se derivaron del estancamiento de la cabaña, agravadas de forma coyuntural por las grandes mortandades de ganado de mediados de siglo - y, quizá también, una mayor diversificación de la demanda en función de calidades y/o precios-, estimularon la exportación de lana procedente de ganado estante o transterminante - lana fina, entrefina e, incluso, de forma fraudulenta, ordinaria-, lo que, a su vez, impulsó el crecimiento de los rebaños con dicha dedicación. Este fenómeno tuvo dos consecuencias de gran trascendencia. Por un lado, se resintió relativamente pronto la calidad media de la lana española dirigida a la exportación y —en la medida en que ello fue fruto del fraude - su estimación en los mercados internacionales, marcando el inicio de una tendencia que se intensificaría y aceleraría, hasta acabar en desastre, tras la Guerra de la Independencia. Por otro, en algunas áreas de invernadero, como Extremadura, los ganaderos trashumantes tuvieron que enfrentarse a la nueva competencia de los estantes exportadores de lana, que, en unión de otros agentes locales, arremetieron contra el privilegio de posesión y alentaron una política de acoso sistemático a los mesteños.

La escasez de pastos, agravada por la aparición de nuevos ganaderos trashumantes y estantes deseosos de participar en el floreciente negocio lanero, desató una amplia y conflictiva competencia por los mismos. La imposibilidad de ampliar los pastizales forzó una redistribución de los disponibles. En lo esencial, dicha redistribución no se operó a través de mecanismos de mercado (aunque éstos se abrieron paso de forma limitada en los arrendamientos de las dehesas de particulares), sino mediante el arbitraje de la Corona, que, buscando un nuevo equilibrio institucional y político, cambió las formas de acceso a los pastos públicos. Así, enajenó grandes dehesas de los maestrazgos —e intentó hacer lo mismo con los baldíos- y cambió la normativa que regulaba el aprovechamiento de los pastos concejiles, para, sin abolir la posesión, anteponer a la misma el derecho de vecindad. Esto último reforzó la capacidad de decisión de las oligarquías locales en materia de asignación de recursos.

En general, la redistribución de pastos favoreció la concentración de la propiedad del ganado. Los grandes ganaderos madrileños y otros de tierras llanas ganaron peso relativo. Sus cabañas son las que más prosperaron durante el Setecientos. 
No obstante, los serranos también crecieron. Los mejor situados de éstos lograron mantener sus posiciones e incluso aumentar el tamaño de sus cabañas. Y ello pese a que su solvencia financiera, con frecuencia, dejaba mucho que desear, de modo que el funcionamiento de sus explotaciones dependía de un recurso continuado al crédito. Sus bazas eran tres: formaban parte de uno de los estamentos privilegiados, con todas las ventajas que se derivaban de ello; monopolizaban los pastos de verano en sus lugares y jurisdicciones de origen, y sus rebaños gozaban de posesión en los invernaderos. En última instancia, su capacidad para mantenerse dentro del negocio se basó, ante todo, en un acceso privilegiado a los pastos.

Los grandes perdedores fueron los pequeños y medianos ganaderos de las sierras. $\mathrm{Si}$, en general, toda dinámica de crecimiento ganadero tendía a perjudicarles, en el siglo XVIII esto resultó especialmente cierto. Sus dificultades para acceder a las hierbas fueron cada vez mayores. Emparedados entre la doble presión de los grandes ganaderos madrileños y de tierras llanas, que acaparaban las hierbas, bien directamente a costa de ellos, bien a costa de los grandes de las sierras - quienes, a su vez, se resarcían despojándoles a ellos-, y de los estantes, que lograron desalojarlos de la mayoría de los pastos concejiles, los serranos más modestos se vieron abocados al abandono de la actividad, a la proletarización -empleándose al servicio de las grandes cabañas- o a su reconversión, en la escasa medida en que ello era posible en las sierras, en estantes con "merinas quedadas". Muchos, no obstante, siguieron dedicándose a la trashumancia en condiciones cada vez más precarias, dependiendo de "acogimientos" o bajando los rebaños a invernar "a sus aventuras", sin pastos previamente contratados. Sus problemas, además, no se circunscribieron a los invernaderos, sino que hubieron de sufrirlos también en los agostaderos de sus propias jurisdicciones de origen. Por otro lado, estos pequeños y medianos ganaderos, muy dependientes del crédito que engrasaba desde el exterior el negocio lanero, sufrieron más que los grandes las dificultades derivadas de las crisis intermitentes que las guerras de finales de siglo causaron en el comercio europeo, así como los problemas financieros interiores, en especial la depreciación de los vales reales. Algunos medianos ganaderos, con mayor capacidad de resistencia, trasladaron su residencia a los invernaderos y/o adquirieron dehesas en propiedad (como hicieron, también, los dueños de grandes cabañas), prefigurando una estrategia que, favorecida por la desvinculación y las desamortizaciones, se acentuaría en el siglo XIX.

El Honrado Concejo resultó debilitado, tanto por las disputas que en torno al acceso a los pastos se suscitaron en su seno, como por la ruina de muchos pequeños y medianos ganaderos. Cada vez fueron más las cuadrillas serranas que no enviaban representantes a las asambleas y que no contribuían en sus repartimientos. Este estrechamiento de su base social hizo que la Mesta perdiera representatividad y legitimidad para la defensa de sus intereses y privilegios - justo cuando éstos eran más cuestionados - frente a otros grupos e instituciones, al tiempo que se resentía su 
capacidad para hacerse presente y actuar en todo el territorio de Castilla. El Honrado Concejo fue quedando reducido a un aparato burocrático cada vez más ineficiente $\mathrm{y}$ en manos de los ganaderos madrileños.

\section{Bibliografía}

ACTAS Y MEMORIAS de la Real Sociedad Económica de los Amigos del País de la Provincia de Segovia, (1783), t. I, Segovia.

ANES, Gonzalo (1970): Las crisis agrarias en la España Moderna, Madrid, Taurus.

BILBAO, Luis María (1998): “Exportaciones de lana española y demanda británica en el siglo XVIII", en RUIZ MARTÍN, Felipe y GARCÍA SANZ, Ángel (eds.), Mesta, trashumancia y lana en la España Moderna, Barcelona, Crítica, pp. 303-331.

-(2001): "Exportación de lanas y finanzas públicas. La política arancelaria en el comercio lanero español, 1750-1827", en GONZÁLEZ ENCISO, Agustín (ed.), El negocio de la lana en España (1650-1830), Pamplona, EUNSA, pp. 347-386.

BOURGOING, Jean François (1803 [1789]), Tableau de l'Espagne moderne, t. I, París (3 ${ }^{a}$ edición) [primera edición, 1789, París].

BRIEVA, Matías (1828): Colección de leyes, reales decretos y órdenes, acuerdos y circulares pertenecientes al ramo de la Mesta desde el año de 1729 al de 1827, Madrid.

CALATAYUD, Pedro de (1761): Tratados, y doctrinas pràcticas, sobre ventas, y compras de lanas merinas, y otros generos; $y$ sobre el juego de naipes, y dados, con un suplemento de veinte y seis contratos, Toledo.

CAMARERO BULLÓN, Concepción (1989): Burgos y el Catastro de Ensenada, Burgos, Caja de Ahorros Municipal de Burgos.

CANGA ARGÜELLES, José (1840): Diccionario de Hacienda con aplicación a España, tomo II, Madrid.

CANO, Alonso (1834 [1762]): “Noticia de la cabaña Real de España", en Biblioteca General de Historia, Ciencias, Artes y Literatura publicada por una Sociedad, t. I, Madrid, pp. 5-33 [original de 1762].

DONÉZAR DÍEZ DE ULZURRUN, Javier María (1984): Riqueza y propiedad en la Castilla del Antiguo Régimen, Madrid, Instituto de Estudios Agrarios, Pesqueros y Alimentarios.

FRANCH BENAVENT, Ricardo (2000): “El abastecimiento de materias primas en la industria textil española del siglo XVIII", en RIBOT GARCÍA, Luis A. y DE ROSA, Luigi (dirs.), Industria y Época Moderna, Madrid, Actas, pp. 63-93.

-(2001): "Los comerciantes valencianos y el negocio de exportación de lana en el siglo XVIII", en GONZÁLEZ ENCISO, Agustín (ed.), El negocio de la lana en España (1650-1830), Pamplona, EUNSA, pp. 201-234. 
FUENTES MORCILLO, Senador (1986): Los propios de Mérida en la segunda mitad del siglo XVIII y primeros años del XIX, Mérida, UNED.

GARCÍA-CUENCA ARIATI, Tomás (1994): Cifras y práctica de la administración y cobranza de la renta de lanas (1749-1789), Cuenca, Universidad de Castilla-La Mancha.

GARCÍA SANZ, Ángel (1994a): “Competitivos en lanas, pero no en paños: lana para la exportación y lana para los telares nacionales en la España del Antiguo Régimen", Revista de Historia Económica, XII, 2, pp. 397-434.

-(1994b): "El siglo XVIII: entre la prosperidad de la trashumancia y la crítica antimesteña de la Ilustración (1700-1808)", en ANES, Gonzalo y GARCÍA SANZ, Ángel (coords.), Mesta, trashumancia y vida pastoril, Valladolid, Sociedad V Centenario del Tratado de Tordesillas, pp. 135-158.

HERNÁNDEZ, Mauro (2002): “El desembarco de los nuevos mesteños en Extremadura: la venta de la dehesa de La Serena y las transformaciones de la trashumancia, 1744-1770", Historia Agraria, 27, pp. 65-100.

HERNÁNZ DE VARGAS, Francisco (1993 [1814]): Memoria sobre el origen y antigüedad de la lana merina y trashumante: y Las causas de que proviene su finura: y los medios de mejorar las lanas bastas en términos de que puedan usarse igualmente que aquella en los paños y demas texidos de nuestras fábricas, Librerías "París-Valencia", Valencia [edición facsímil de la de Madrid de 1814].

KLEIN, Julius (1936): La Mesta. Estudio de la historia económica española, 1273-1836, Madrid, Revista de Occidente.

LARRUGA Y BONETA, Eugenio (1787-1800): Memorias politicas y económicas sobre los frutos, comercio, fábricas y minas de España: con inclusión de los reales decretos, órdenes, cédulas, aranceles y ordenanzas expedidas para su gobierno y fomento, Madrid.

LASTEYRIE, Charles Philibert (1799): Traité sur les bétes-a-laine d’Espagne; leur éducation, leurs voyages, la tonte, le lavage et le commerce des laines, les causes qui donnent la finesse aux laines: Auquel on a ajouté l historique des voyages que font les moutons des Bouches-du-Rhône, et ceux du royaume de Naples; l'origine, les succès, l'état actuel du troupeau de Rambouillet, et les moyens de propager et de conserver la race espagnole dans toute sa pureté, París.

LINARES LUJÁN, Antonio Miguel (1995): “De la apropiación del usufructo a la privatización de la superficie. Las tierras concejiles en la Baja Extremadura (17501850)", Noticiario de Historia Agraria, 9, pp. 87-127.

LLOPIS AGELÁN, Enrique (1982): “Las explotaciones trashumantes en el siglo XVIII y primer tercio del XIX: la cabaña del monasterio de Guadalupe, 1709-1835", en ANES, Gonzalo (ed.), La economía española al final del Antiguo Régimen. I. Agricultura, Madrid, Alianza Editorial, pp.1-101.

—(1989): "El agro extremeño en el Setecientos: crecimiento demográfico, «invasión mesteña» y conflictos sociales", en Estructuras Agrarias y Reformismo lustrado en 
la España del siglo XVIII, Madrid, Ministerio de Agricultura, Pesca y Alimentación, pp. 267-290.

-(1993): "La cabaña trashumante del monasterio de Guadalupe: historia, funcionamiento y resultados", en Trashumancia y cultura pastoril en Extremadura, Mérida, Asamblea de Extremadura, pp. 107-129.

-(2002): "Expansión, reformismo y obstáculos al crecimiento (1715-1789)", en COMÍN, Francisco; HERNÁNDEZ, Mauro y LLOPIS, Enrique (eds.), Historia económica de España. Siglos X-XX, Barcelona, Crítica, pp. 121-164.

-(2003): "La agricultura, 1790-1840: de la crisis a la gran oleada roturadora", en MORALES, Antonio (coord.), 1802: España entre dos siglos. Ciencia y Economía, Madrid, Sociedad Estatal de Conmemoraciones Culturales.

MARCOS MARTÍN, Alberto (2000): España en los siglos XVI, XVII y XVIII. Economía y sociedad, Barcelona, Crítica.

MATILLA TASCÓN, Antonio (1950): Catálogo de la colección de Órdenes Generales de Rentas (Aportación para la Historia de los tributos y del comercio españoles), Madrid, Servicio de Estudios de la Inspección General del Ministerio de Hacienda.

MELÓN JIMÉNEZ, Miguel Ángel (1989): Extremadura en el Antiguo Régimen. Economía y sociedad en tierras de Cáceres, 1700-1814, Mérida, Editora Regional de Extremadura.

-(1992): Los orígenes del capital comercial y financiero en Extremadura. Compañias de comercio, comerciantes y banqueros de Cáceres (1773-1836), Badajoz, Diputación Provincial de Badajoz.

MEMORIAL AJUSTADO, hecho en virtud de decreto del Consejo, del expediente consultivo, que pende en el, en fuerza de Real Orden, comunicada por la Secretaria de Estado, y del Despacho Universal de Hacienda, con fecha en San Ildefonso de 20 de Julio del año de 1764. Entre Don Vicente Paino y Hurtado, como Diputado de las Ciudades de Voto en Cortes, Badajoz, Merida, Truxillo, y su Sexmo, Llerena, el Estado de Medellin, y Villa de Alcantara, por sí, y toda la Provincia de Extremadura: y el Honrado Concejo de la Mesta General de estos Reynos: en que intervienen los señores fiscales del Consejo y Don Pedro Manuel Saenz de Pedroso y Ximeno, Procurador General del Reyno. Sobre que se pongan en práctica los diez y siete Capitulos, ó medios, que en representacion, puesta en las Reales manos de S.M. propone el Diputado de las Ciudades, y Provincia de Estremadura, para fomentar en ella la Agricultura, y cria de Ganados, y corregir los abusos de los Ganaderos trashumantes, (1771), Madrid.

MEMORIAL AJUSTADO del expediente de Concordia que trata el Honrado Concejo de la Mesta con la Diputación General del Reino y provincia de Extremadura ante el Ilustrísimo señor Conde de Campomanes, del Consejo y Cámara de S.M., su primer Fiscal, y Presidente del mismo Honrado Concejo, (1783), Madrid.

NOVÍSIMA RECOPILACIÓN de las leyes de España (1803), Madrid. 
PÉREZ CABALLERO, Bernardo (1796): Razones prácticas para que los apoderados de los ganaderos transhumantes de Soria usen de las que les convenga, para satisfacer a la representacion que hizo al Ayuntamiento de la Ciudad de Cordoba Don Francisco Salgado y Salcedo, siendo Diputado del Comun de ella en once de Mayo de mil setecientos noventa y quatro: Sobre que se ponga en uso la Ordenanza y Privilegio que tiene dicha Ciudad, para que desde el Castillo de Bacár hasta Peña-flor no entren á Hervajar los Ganados Mesteños en la Campiña, y territorios que comprenden los Pueblos interesados en el asunto, que se nominan en dicha Representacion, para lo que fueron convocados, é instruídos, con una Copia impresa de dicha Representación, por acuerdo de dicha Ciudad de cinco de Marzo de mil setecientos noventa y cinco, Soria.

PÉREZ ROMERO, Emilio (1995): Patrimonios comunales, ganadería trashumante y sociedad en la Tierra de Soria, siglos XVIII-XIX, Valladolid, Junta de Castilla y León.

-(1996): "Trashumancia y pastos de agostadero en las sierras sorianas durante el siglo XVIII", Revista de Historia Económica, XIV, 1, pp. 91-124.

-(2001): "Trashumancia, comercio lanero y crédito. La Compañía de Ganaderos de las Provincias de Soria y Burgos (1781-1800)", Historia Agraria, 23, pp. 119-146.

PHILLIPS, Carla Rahn y PHILLIPS, William D., jr. (1997): Spain's Golden Fleece. Wool production and the Wool Trade from the Middle Ages to the Nineteenth Century, Baltimore and London, The John Hopkins University Press.

RUPÉREZ ALMAJANO, Nieves (1987): La Sociedad Económica de Amigos del País de Soria (1777-1809). Estudio institucional, Soria, Diputación Provincial de Soria.

SÁNCHEZ SALAZAR, Felipa (1988): Extensión de cultivos en España en el siglo XVIII. Roturas y repartos de tierras concejiles, Madrid, Siglo XXI-Ministerio de Agricultura, Pesca y Alimentación.

SEBASTIÁN AMARILLA, José Antonio (2004): “La agricultura española y el legado del Antiguo Régimen", en LLOPIS, Enrique (ed.), El legado económico del Antiguo Régimen en España, Barcelona, Crítica, pp. 147-186.

TOMO TERCERO DE AUTOS ACORDADOS que contiene nueve libros, por el orden de titulos de las Leyes de Recopilación, i vàn en èl las Pragmáticas, que se imprimieron el año de 1723. al fin del Tomo tercero todos los Autos acordados del Tomo quarto de ella, i otras muchas Pragmáticas, Consultas resueltas, Cedulas, Reales Decretos, i Autos Acordados, que se han aumentado, (1982 [1745]), Valladolid, Lex Nova [edición facsímil de la de 1745].

UZTÁRIZ, Gerónimo de (1968 [1742]): Teórica, y Práctica de Comercio y de Marina, Madrid, Aguilar [edición facsímil de la $2^{\mathrm{a}}$ ed., de 1742].

ZAPATA, Baltasar Antonio (1820): Noticias del origen y establecimiento increible de las lanas finas de España en el extrangero, por culpa nuestra en no haber impedido mejor la extracción de nuestro ganado lanar, Madrid. 